\title{
Students Impression About Using Mobile Phones in Classroom
}

https://doi.org/10.3991/ijet.v15i22.16219

\author{
Batoul Al Fakih, Anwar Morei, Mohammad Salehi M( $\left.{ }^{\varpi}\right)$ \\ Qatar University, Doha, Qatar \\ salehilqu.edu.qa
}

\begin{abstract}
Mobile phones are widely used by university students and there is a controversial topic whether students should be able to use them freely during lectures. A survey was distributed seeking student opinions on using mobile phones in classroom. We used two-phase sampling method to reduce the nonresponse bias. There were 392 valid responses. To test the effect of different factors on students' opinions a number of statistical techniques were utilized. The results showed Qatar University students marginally favored using mobile in classroom, but using mobile phone distracted some students who are less in favor of using phone during lectures. The proportion of students who believe that student should decide to use or not use mobile in the classes is 0.635. Apparently, students expected implementation of a policy that controls the use of mobile phones in class. Recommendations include a blanket policy for the University on the use of mobile phones during class, mobile phone breaks given by lecturers during class, utilizing mobile phone as an educational tool, with social media distractions blocked through the university system.
\end{abstract}

Keywords—Phone separation anxiety, social media, two-phase sampling

\section{Introduction}

Mobile phones have rapidly become a form of technology that merged seamlessly with public demand, people like to talk, and mobile phones allow them to do so from almost anywhere. The technology however, kept on developing, until mobile phones became portable computers that are able to connect people all over the world through voice and video calls, virtually transporting people to different countries (virtual travel being a thing these days). However, the most important feature a mobile phone serves, is the availability of infinite data instantly, typing a single word into a search engine will retrieve hundreds of articles, journals and images etc. relating to the phrase. Learning via mobile phones has become one of the most popular teaching tools used by young generation, which is the result of friendly use of such devices in the field of education. Lotfi has recently designed a platform for learning outcomes analysis dictated for mobile serious games, with a global aim to offer both easy and efficient tool to the instructor, that will help them during the work with learners in order to, acquire new skills [1]. With the new generation of mobiles, one may even use MS Excel, which can be used as a very powerful calculator or statistical software in the class [2]. 
All features that a mobile phone provides has made them one of the most important tools a university student can acquire. According to the survey undertaken, a hundred percent of the QU students who completed the survey possess at least one mobile phone. This was the expected result, which is why the study of the relationship between mobile phones and QU students' education, the causes, the effects and the benefits is of significant interest.

Three major drawbacks related to using mobile technologies in teaching are distraction, cheating, and teacher perception and readiness [3]. The survey results shows that students are considering mobile phones as a distraction tool in the class, hence many instructors do not allow their use during the class time, and would take offence when a student use one during the lecture. However, other lecturers do not put rules for the use of mobile phones during lectures, yet it has been found within the survey that students pass these courses and get high grades.

A study conducted in Serbia by Körösi and Esztelecki aimed to analyse the relationship between the time spent on mobile phones and the purpose of it among students and teachers across Vojvodina [4]. A questionnaire was distributed to 455 students and 49 teachers. The main question was about the participants' opinions on the potentials of their utilization of their smartphones in class and in what purposes. The hypothesis of the paper was that teachers would be unconvinced with the technology, especially those who do not own a smartphone. The main findings of the study were that most teachers do not allow the use of mobile phones during classes. Another finding of the study is that students who use mobile phones during class use them to gather information, take notes and potentially cheat, which could be the main reason why most teachers do not support the use of mobile phones in class.

\section{Literature Review}

Begum studied whether mobile phones can be used as a potential tool to teach English language in Jahangirnagar University, Dhaka, Bangladesh [5]. Due to cheap price of mobile phones, they are a good replacement to expensive laptops, which cannot be afforded by the university nor the students. A hundred first year undergraduate students attending Jahangirnagar University were observed, and five teachers from the English department were included in the study. The results showed that using mobile phone is an effective tool in language learning, and the researchers advised the university to encourage teachers as well as students to use mobile phones as a learning tool. Persson and Nouri have comprehensively reviewed researches done on the second language learning with mobile technologies since 2010 [6]. Dashtestani carried out a survey on Iranian students and instructors and he suggested that even though some Iranian English as foreign language teachers favor the use of mobile devices in the classroom, some of them prevent students from such use [7]. In light of students' proposed strategies to implement mobile learning, the study suggests guidelines to integrate mobile learning in the EFL context of Iran and other similar contexts.

Dong studied mobile phone use behavior by university students [8]. The intervening variable was mobile phone addiction, while the predictor variables were self-esteem, social extraversion and anxiety. They collected a sample of 269 valid questionnaires, from female undergraduate students from three different universities in Taiwan. The 
result shows that social extraversion and anxiety have positive effects on mobile phone addiction, and self-esteem has negative effects on mobile phone addiction whilst mobile phone addiction has a positive predictive effect on mobile phone usage behaviour. The results of the study identify personal psychological characteristics of Taiwanese female university students, which can significantly predict mobile phone addiction; female university students with mobile phone addiction will make more phone calls and send more text messages.

Li conducted a study on students enrolling in a technical college to understand how mobile phones affect teaching in classrooms [9]. A total of 1,598 questionnaires were issued, and 1,315 were returned. There have been 1,296 successful questionnaires, $82 \%$ of the total. This questionnaire featured five modules. The survey results shows that students share a similar view of how to use mobile phones in class. Under good management and control, $56.34 \%$ of students accepted mobile phone use in class. $52.69 \%$ believed that using mobile phones would have a major influence on class study, while $37.63 \%$ believed that their influence is negative but relatively small. That is, up to $90.3 \%$ of the students agreed that this behavior would have an impact on class study. Combining these statistics, the author concluded that using mobile phone in class is widely accepted by students, while students who also understand the negative impact it brings up. Therefore, instructors respect the reality and inevitable trend that mobile terminals have already coexisted with classroom teaching. The traditional management and practice such as taking away students' mobile phones or prohibiting bringing mobile phones to class is outdated. Instructors should take the advantage of the students' physiological awareness that "using mobile phone affects class study indeed", follow their desires and instruct them to use mobile phone in class in a more appropriate way [10].

Turner carried out a study to find out why students choose to use their mobile phones during class rather than concentrating on their learning in Vancouver Island University [11]. Knowing the reasons behind the choices made by students can provide the basis for educating students about how their choices affect their learning as well as others' learning. The author conclude that educational leaders must be aware of student behavior and attitude and be prepared to adapt policies as necessary in order to enhance student learning.

\section{Methodology}

\subsection{Survey}

More than forty questions were prepared, which have been modified to fit the timeline, culture, and purpose of the survey. The second step was to set up a model for the pilot survey, narrowing down the questions to 25 . The final questionnaire is given in the Appendix. Two questions mostly reflect the students' impression about using mobile phones in the classroom;

Question 22, "Do you think as a university student, you should be allowed to decide whether used or do not use your mobile phone in classroom? 1. Yes, 2. No." 
Question 23 "Rate your opinion on the use of mobile phone in the classroom. Students could rate it from 1 to 10 where $1=$ it should not be used at all, and $10=$ it must be used.

In the early stages, there was a problem in posting the survey link on Twitter, which would have established a random sample database. This was overcome by utilizing other social media forums to students across QU. It was important to ensure the inclusion of students from various majors, encouraging students to share the survey with classmates. This allowed us to secure a diverse population coverage for the data collected. The pilot yielded 62 responses.

Following the successful trial of the pilot survey, the process of composing the main survey was started. This was a big step with several round of trial and error to ensure that there was sufficient data to allow for a comprehensive statistical analysis. Over two phases 414 responses were received. We used a follow-up two-phase sampling technique in which takes out information from nonresponse population in phase two [12]. We implement a simple version of the method introduced by Hassan [13]. The first phase was to send the link to the students through Twitter. In the first phase, we had 110 responses. In phase 2, the Institutional Survey Research of Qatar University (QU) distributed the survey to QU students via their university emails. The survey was sent to half the population, randomly. From phase two, we collected 304 responses. In total, there were 392 valid responses.

\subsection{Data analysis}

The data was analyzed using SPSS, Minitab and Excel. Different types of statistical tests were utilized. For some questions with more answer choices, we merged some answer choices in the analyzing step to get results that are more reliable. For example, the answer choices were 10 for colleges but we considered College of Art and Science, College Business, College of Engineering and we merged all smaller colleges into one option of "Others". The results showed that two-phase techniques helped to reduce the bias. The proportion of "Yes" answer to question 22 was 0.59 for the response population in phase 1 . That sample proportion was 0.648 in phase 2 . Using nonparametric binomial test, the p-value is 0.038 , which means that the proportions are significantly different at $\alpha=0.05$, and the second phase helped to reduce the bias. The implemented two-phase technique also balanced the representation of different groups of students in the final sample. For example, the male proportion was only 0.03 in the first phase and that proportion was 0.18 in the second phase. The p-value for testing that the proportions are different is 0.000 which means that the second phase makes the sample more representative. This was the case, for 16 multiple choice questions out of 22 questions.

To test the effect of each question on the opinion of students about using mobile phones in classroom, which was extracted from question 23 , we have used different statistical tests as follows. When the answer choices were only two options, we used ttest if the observed opinion rates of each option are normally distributed. Otherwise, we used its nonparametric counterpart Mann-Whitney test. When the answer choices are more than two, one-way ANOVA was used. Whenever the adequacy of model were violated and the transformation, using Box-Cox method, did not work out, we used the nonparametric counterpart of one-way ANOVA, which is Kruskal-Wallis test. We then 
used stepwise factorial design to find out the most important factors affecting the opinion of students on using mobile phones in classroom. We then used logistic regression to analyse students' opinion on whether or not to use their mobile phones in the classroom.

\section{$4 \quad$ Results}

It was noticed that the mean score of students' opinions on using mobile phone in classroom at QU is 5.54 out of 10 and its $95 \%$ confidence interval is $(5.25,5.83)$. It shows that students are narrowly in favor of using mobile in the classroom. However, it seems that students from different genders have different opinions; to be precise, male students favored the use of mobile phone in class more than females. The results of 16 factors (questions) effects on students' opinion scores are given in Table 1. Table 1 shows that there is a significant difference between male and female opinion scores. The mean of males is 6.25 while it is 5.36 for females. Among 16 factors tested, 10 factors have significant effects on the opinion scores.

The most significant factor affecting their opinion scores is the opinion of students about having the right of using or not using mobile phone in the class (Q22). It is quite expected, as both questions were design to discover students' opinions on using mobile phone in the class. As expected, those students who think they should be allowed to use or not to use their mobile phones in classroom have significantly higher opinion score then students who do not think so. The next factor is the opinion of students on improvement in learning. After that, the factor of distraction (Q17) which is whether a classmate distracted them in classroom. Distraction by other classmates' phones had significant effect on the student's opinion about the use of mobile phones in class, in general. Students who were distracted by their classmates' phones had less mean opinion scores than those who were not distracted, but a deeper analysis showed that only female students who were distracted scored less, while male distracted students did not affect their opinion. The mean was 4.71 for distracted students while it was 6.10 for not distracted students. Another significant factor is their idea about the improvement on their grades caused by using mobile phones in the class. The means are 7.21, 6.62 and 5.06 for students who think that their grades improved a lot, a little and none, respectively. To find these most significant factors we construct a general linear model using stepwise techniques, which end up with those four factors. The ANOVA table of that analysis is given in Table 2. The original model was not adequate and the results in Table 2 is after transformation.

Some other significant factors affecting students' opinion scores are college, time spent on phone in classroom, registering in a class that use of mobile phone is not allowed. College of engineering students had the highest mean of 6.20. Those students who spent between 2 to 20 minutes on their mobile phone in classroom had significantly higher score those students who did not use it at all or used it for more than 20 minutes. Those students willing to register in a class that instructors do not allow the use of mobile phone in class have the smallest mean of 4.96 while the mean of students who would not register and, register if they have to, are 6.15 and 6.86 , respectively. 
Table 1. Summary of test of effect of different factors on the opinion of students on using mobile phone in the classroom.

\begin{tabular}{|c|c|c|c|}
\hline Questions (\#) & Mean of score & Questions (\#) & Mean of score \\
\hline $\begin{array}{l}\text { 1. Gender } \\
\text {-Male } \\
\text {-Female }\end{array}$ & $\begin{array}{c}\text { P-value: } 0.017 * 1 \\
6.25 \\
5.36\end{array}$ & $\begin{array}{l}\text { 13. Mobile Use } \\
\text { Emergency call } \\
\text { Access to lecture } \\
\text { Recording the lecture } \\
\text { Blackboard } \\
\text { Others }\end{array}$ & $\begin{array}{c}\text { P-value: } 0.21^{\# 2} \\
5.49 \\
5.25 \\
5.11 \\
6.22 \\
5.60 \\
\end{array}$ \\
\hline $\begin{array}{l}\text { 2. Nationality } \\
\text { Qatari } \\
\text { Middle-eastern } \\
\text {-other }\end{array}$ & $\begin{array}{c}\text { P-value: } 0.692^{\# 3} \\
5.86 \\
5.45 \\
5.56\end{array}$ & $\begin{array}{l}\text { 14.Policy } \\
\text {-use for education } \\
\text {-Reply to messages } \\
\text {-Check anytime } \\
\text {-Other }\end{array}$ & $\begin{array}{c}\text { P-value: } 0.002 * 4 \\
5.25 \\
6.57 \\
6.52 \\
4.46 \\
\end{array}$ \\
\hline $\begin{array}{l}5 . \text { Years } \\
1 \\
2 \\
3 \\
3.5>=\end{array}$ & $\begin{array}{c}\text { P-value: } 0.238^{\# 3} \\
5.64 \\
5.80 \\
5.37 \\
4.83\end{array}$ & $\begin{array}{l}\text { 15. Time spent } \\
-2-5 \text { minutes } \\
-6-10 \text { minutes } \\
-11-20 \text { minutes } \\
- \text { more than } 20 \text { minutes } \\
\text {-not used in class time }\end{array}$ & $\begin{array}{c}\text { P-value: } 0.000 * 4 \\
6.05 \\
6.25 \\
6.41 \\
4.33 \\
4.37\end{array}$ \\
\hline $\begin{array}{l}\text { 6.Current Grades } \\
\text { More than } 3.5 \\
3-3.5 \\
2.5-3 \\
2-2.5 \\
\text { Less than } 2 \\
\end{array}$ & $\begin{array}{c}\text { P-value: } 0.559^{\# 3} \\
5.21 \\
5.77 \\
5.70 \\
4.82 \\
5.78 \\
\end{array}$ & $\begin{array}{l}\text { 16.Improvement in } \\
\text { Learning } \\
\text { Yes } \\
\text { No } \\
\text { Maybe } \\
\text { Others } \\
\end{array}$ & $\begin{array}{c}\text { P-value }=0.000 * 3 \\
7.08 \\
4.81 \\
6.35 \\
4.37\end{array}$ \\
\hline $\begin{array}{l}\text { 7.College } \\
\text {-Arts and Science } \\
\text {-Business } \\
\text {-Engineering } \\
\text {-other } \\
\end{array}$ & $\begin{array}{c}\text { P-value: } 0.024 * 4 \\
5.60 \\
5.77 \\
6.20 \\
4.95 \\
\end{array}$ & $\begin{array}{l}\text { 17. Distracted } \\
\text { Yes } \\
\text { No }\end{array}$ & $\begin{array}{c}\text { P-value: } 0.000 * 1 \\
4.71 \\
6.10\end{array}$ \\
\hline $\begin{array}{l}\text { 10. Phone separation } \\
\text { anxiety } \\
\text { Yes } \\
\text { No } \\
\end{array}$ & $\begin{array}{c}\text { P-value: } 0.185^{\# 1} \\
5.81 \\
5.38\end{array}$ & \begin{tabular}{|l|} 
19. Improvement in Grade \\
-Yes, a lot \\
-Yes, a little \\
-No, not affected \\
\end{tabular} & $\begin{array}{c}\text { P-value:0.000*4 } \\
7.206 \\
6.615 \\
5.060 \\
\end{array}$ \\
\hline $\begin{array}{l}\text { 11. Phones can replace a } \\
\text { laptop } \\
\text {-Yes } \\
\text {-No } \\
\text {-Maybe } \\
\end{array}$ & $\begin{array}{c}\text { P-value: } 0.330^{\# 3} \\
5.704 \\
5.288 \\
5.748 \\
\end{array}$ & \begin{tabular}{|l|} 
21. Register in a class \\
Phone \\
Yes \\
No \\
Yes, if no other option \\
\end{tabular} & $\begin{array}{c}\text { P-value: } 0.000 * 3 \\
4.96 \\
6.15 \\
6.86\end{array}$ \\
\hline $\begin{array}{l}\text { 18.Mobile in Exam } \\
\text { Yes } \\
\text { No }\end{array}$ & $\begin{array}{c}\text { P-value: } 0.330^{\# 2} \\
4.81 \\
5.58\end{array}$ & $\begin{array}{l}\text { 22. Decide to use } \\
\text { Yes } \\
\text { No }\end{array}$ & $\begin{array}{c}\text { P-value: } 0.000 * 1 \\
6.38 \\
3.98\end{array}$ \\
\hline
\end{tabular}

\#Difference is not significant *Difference is significant; 1: t-test, 2: Mann-Whitney test, 3:One-Way ANOVA, 4: Kruskal-Wallis test. 
Table 2. The ANOVA table for step-wise technique

\begin{tabular}{|l|c|c|c|c|c|}
\hline \multicolumn{1}{|c|}{ Source } & DF & Adj SS & Adj MS & F-Value & P-Value \\
\hline Improvement in learning & 3 & 15.746 & 5.2486 & 5.42 & 0.001 \\
\hline Distraction & 1 & 8.225 & 8.2253 & 8.49 & 0.004 \\
\hline Improvement in Grades & 2 & 7.769 & 3.8844 & 4.01 & 0.019 \\
\hline Right to use mobile & 1 & 44.212 & 44.2122 & 45.61 & 0.000 \\
\hline Error & 313 & 303.376 & 0.9693 & & \\
\hline Lack-of-Fit & 30 & 28.493 & 0.9498 & 0.98 & 0.504 \\
\hline Pure Error & 283 & 274.883 & 0.9713 & & \\
\hline Total & 320 & 444.325 & & & \\
\hline
\end{tabular}

Table 3 shows the different uses of the mobile phones by male and female students during class, and it can be noticed that most of the male and female students use their phones in class mainly to register attendance, but for male students the second option was emergency phone calls, while for female students it was recording lectures. Hence, it can be concluded that female students use their phones in class for educational purposes. On the contrary, more female students (almost double the percentage) responded that they do not use their mobile phones in classrooms.

Table 3. Distribution of the uses of mobile phones by students according to their gender.

\begin{tabular}{|l|c|c|}
\hline \multicolumn{1}{|c|}{ Importance } & \multicolumn{2}{c|}{ Gender } \\
\hline Emergency phone calls & $13(19.7 \%)$ & Female \\
\hline Googling important topics & $6(9.1 \%)$ & $23(7.1 \%)$ \\
\hline Recording lectures & $8(12.1 \%)$ & $60(18.4 \%)$ \\
\hline Calculator translation apps and others & $8(12.1 \%)$ & $25(7.7 \%)$ \\
\hline Notes apps and lecture notes & $10(15.2 \%)$ & $14(4.3 \%)$ \\
\hline To register attendance & $16(24.2 \%)$ & $107(32.8 \%)$ \\
\hline I do not think it is important & $5(7.6 \%)$ & $50(15.3 \%)$ \\
\hline Total & $66(100 \%)$ & $326(100 \%)$ \\
\hline
\end{tabular}

Thirty eight percent of QU students suffer from Phone Separation Anxiety (PSA), it is a case where a person feels the need to check his/her phone constantly. However, the opinion of the students who suffer from PSA and those who do not was not significantly different. Even though, it was clear that people suffering from PSA use their mobile phones for longer times in class. It may show that their PSA is under their control and their opinions are not affected by their desire.

The proportion of students who think that they should choose whether to use their mobile phone in class or not is $63.5 \%$. Its $95 \%$ confidence interval is $(0.61,0.66)$. It means that the majority of students' desire to have the right of using or not using their mobile phones in the class. This increases to $71 \%$ among male students. However, the $\mathrm{p}$-value of chi-square test for association is 0.095 so that the difference is not significant at $\alpha=0.05$. However, we use logistics regression to find out whether this proportion can be predicted utilizing students' opinion scores for using mobile phone in classroom. The fitted model is

$$
\pi=\frac{e^{-1.486+0.405 x}}{1-e^{-1.486+0.405 x}}
$$


where $x$ is the students' opinion score and $\pi$ is the probability that students desires to have the right of using or not using their mobile phone in the class. The Wald statistics is 50.037 and the p-value is 0.000 . Therefore, the score can predict the probability that student's answer to question 22 is "Yes". This model can also be a sort of test for reliability of questionnaire.

\section{Conclusion}

The survey undertaken showed that male students encourage the use of mobile phones in class more than female students do, even though female students use it more for educational purposes, while male students use it for phone calls. Students are conservatively in favor of using mobile phone in classroom but they have some reservations including being distracted or losing their concentration in the class.

Students who have different GPA's have almost the same opinion about the use of mobile phones in classrooms, we may allude that to the fact that mobile phones can be used as an educational tool as well as it is a distraction factor from students' point of view.

Students who were distracted by their friends had a mean opinion score on the use of phones, which favored the presence of a policy. Students with phone separation anxiety had the same opinion as those who do not suffer from it. However, they are using their mobile phones more in class, and this may mean that these students are willing to stop using their mobile phones in classrooms if a policy is implemented that enforces and limits the use of mobile phones in class. It shows that students are concerned about their education and willing to respect university regulations.

The majority of students desired to decide using or not using their phone in class. We must not consider using mobile phones by students in class as a danger to education at all and we should accept the inevitable fact that students will use their mobile phones in the class. It is almost impossible to prevent them to use it, as the technology development is so fast and in favor of smartphone users who want to hide their activities on phone from others. This study shows students are aware of the negative effect of using mobile phones in class so a soft and smooth supervising behavior will help to take advantage of educational applications and reduce the usage of non-educational applications in the class.

Adopted a blanket policy about the use of mobile phones in class by the university can be useful, given that the required technology and equipment are provided. Instructors monitor the students' activities on their mobile phones in class while try to take full advantage of positive educational benefit it. A few minutes break in the middle of class may help students who use their mobile phones for non-educational purposes.

\section{Acknowledgement}

We would like to express our appreciation to Dr. Mamood Hassan, Ms. Ameena Al Abdullh, Ms. Alaa Ibrahim, Ms. Samiya Albalushi and Ms. Ihoud Ibrahim for their help. 


\section{$7 \quad$ References}

[1] Lotfi E. (2020). Towards a New Platform Based on Learning Outcomes Analysis for Mobile Serious Games. International Journal of Emerging Technologies in Learning. Volume 15, Issue 2, https://doi.org/10.3991/ijet.v15i02.11637

[2] Salehi, M. M. (2016). Using MS Excel in teaching Design of Experiment, International Journal of Education and Learning Systems, Vol 1, 93-98. https://www.iaras.org/iaras/ filedownloads/ijels/2016/002-0013.pdf

[3] Metruk R. (2020). Confronting the Challenges of MALL: Distraction, Cheating, and Teacher Readiness. International Journal of Emerging Technologies in Learning. Volume 15, Issue 2, https://doi.org/10.3991/ijet.v15i02.11325

[4] Körösi, G., \& Esztelecki, P. (2015). Implementation of mobile phones in education. Research in Pedagogy, 5(1), 98-108. https://doi.org/10.17810/2015.08

[5] Begum, R. (2011). Prospect for Mobile Phones as Instructional Tools in the EFL classroom: a Case Study of Jahangirnagar university, Bangladesh. 4(1), 105-115. https://files.eric.ed.gov/fulltext/EJ1080334.pdf https://doi.org/10.5539/elt.v4n1p105

[6] Persson V. and Nouri J. (2018). A Systematic Review of Second Language Learning with Mobile Technologies. International Journal of Emerging Technologies in Learning. Vol 13, No 02 (2018) https://doi.org/10.3991/ijet.v13i02.8094

[7] Reza Dashtestani (2016) Moving bravely towards mobile learning: Iranian students' use of mobile devices for learning English as a foreign language, Computer Assisted Language Learning, 29:4, 815-832, https://doi.org/10.1080/09588221.2015. $\underline{1069360}$

[8] Dong Z. (2015). The Influence of Mobile Phones in Vocational College Classroom and Coping Strategies. Journal of Huinan Vocational \& Technical College.1(15): 58-61. https://www.oriprobe.com/journals/hnzyjsxyxb/2015_1.htm

[9] Li, L. (2018). Survey \& Research on Mobile Terminals in Classroom Teaching. Journal of Physics: Conference Series, 1060, 012045. https://doi.org/10.1088/17426596/1060/1/012045

[10] Kuznekoff, J. H., Munz, S., \& Titsworth, S. (2015). Mobile Phones in the Classroom: Examining the Effects of Texting, Twitter, and Message Content on Student Learning. Communication Education, 64(3), 344-365. https://doi.org/10.1080/03634523. $\underline{2015.1038727}$

[11] Turner, R. (2011). Student use of cell phones in the classroom. Leadership Research: Horizons, 2(1). https://pdfs.sematicscholar.org/0ece/c3f325c73e209e3f6c2945c8b1a4ce271f72.pdf

[12] Thompson S.K. (2012). Sampling ( $3^{\text {rd }}$ ed). Wiley: New York.

[13] Hassan (2019). Developing A Two-Phase Post-Stratified Inverse Sampling to Reduce The Nonresponse Bias: Students' Satisfaction Survey in Qatar University, (Master Thesis), Qatar University, Doha, Qatar. http://hdl.handle.net/10576/11664

\section{Authors}

Batoul Al-Fakih is a graduate of Qatar University, with a bachelor degree in statistics. She is a member of Royal Statistics Society.

Anwar Morei is a student at Qatar University, faculty of statistics. 
Mohammad Salehi is a professor of statistic at Department of Mathematics Statistics and Physics, College of Arts and Sciences, Qatar University, PO. Box 2713, Doha, Qatar. His research interests are statistics analysis, sampling design and their application in different fields including education, environmental sciences, engineering, medical sciences and optimal switching. Email id: salehi@qu.edu.qa

Article submitted 2020-06-11. Resubmitted 2020-07-08. Final acceptance 2020-07-09. Final version published as submitted by the authors. 


\section{Appendix: Questionnaire}

1. What is your gender?

$>$ Male

$>$ Female

2. What is your nationality?

$>$ Qatari

$>$ Middle-eastern (Non-Qatari)

3. What is your age?

19 or under

20-24

25-29

30 or over

4. Are you currently enrolled in Qatar University?

Yes

No

5. How many semesters have you finished?

$>1-2$

$>3-4$

$>5-6$

$>7$ or more

6. What is your current GPA?

$>$ More than 3.5

3-3.5

2.5-3

2-2.5

$>$ less than 2

7. What is your college?

$>$ Foundation Program

$>$ College of Arts and Science

$>$ College of Business and Economics

$>$ College of Education

$>$ College of Engineering

$>$ College of Law

$>$ College of Health Sciences

$>$ College of Medicines 
$>$ College of Pharmacy

$>$ College of Sharia and Islamic Studies

8. How much time do you spend on your mobile phone on average during a day?

$30 \mathrm{~min}$ or less

$>1-2$ hours

$>2-3$ hours

$>$ 3-4 hours

$>$ 4-5 hours

$>$ more than 5 hours

9. What do you mostly use your mobile phone for?

Social media (Facebook, twitter, Instagram...)

Texting

$>$ Calling

$>$ Games

$>$ e-learning

10. Do you have phone separation anxiety? (Would you feel stressed if you were not able to check your phone constantly?)

$>$ Yes

$>$ No

11. Do you think a mobile phone can replace a laptop in a classroom?

$>$ Yes

$>$ No

$>$ Maybe

12. Why do you prefer using a mobile phone rather than a laptop in class?

Easier to carry

$>$ Laptops take more time to start

$>$ Phones are easier to use

$>$ Phones are more affordable

13. Why do you think it is important to use mobile phones in class?

$>$ Emergency phone calls

$>$ Googling important topics

$>$ Recording the lecture

$>$ Using translation applications

$>$ Using calculator

$>$ Using notes applications

$>$ Opening the lecture notes or books

$>$ Opening blackboard for taking the attendance

لا أعتقد أنه دهم / I do not think it is important 
14. What do you think should be the policy on using mobile phones in class?

To be able to use it for educational purposes only

To be able to reply to text messages and phone calls

To be able to check at any time

15. How much time do you spend on your phone during class time?

$2-5 \mathrm{~min}$

$>6-10 \mathrm{~min}$

$>11-20$

$>$ more than $20 \mathrm{~min}$

I do not use my phone during class time

16. Do you think that using the mobile phone in class has improved your ability to learn?

$>$ Yes

$>$ No

$>$ Maybe

17. Have you ever been distracted by another student using his/her phone during class?

$>$ Yes

$>$ No

18. Have you ever used your mobile phone during an exam?

$>$ Yes

$>$ No

19. Did you find that using a phone during class has improved your grades?

Yes, my grades improved a lot

Yes, my grades improved a little bit

No, my grades were not affected

20. In which situation do you think the students can use their phones without the instructor being aware?

$>$ If the instructor writes on the blackboard

$>$ If the instructor does not give or pay attention

$>$ all of the above

$>$ no situation

21. Will you register a class with an instructor who will not allow the use of mobile phones in class for any reason?

$>$ Yes

No

Yes, in case I have no other option 
22. Do you think as a university student, you should be allowed to decide whether use or do not use your mobile phone in classroom?

Yes

No

23. Rate your opinion on the use of mobile phones in the classrooms $(1=$ not satisfied at all, 10= satisfied)

24 . Rate your satisfaction regarding your instructor's policies and behaviour towards using mobile phones in the class ( $1=$ not satisfied at all, 10=very satisfied)

25 . Rate your opinion about QU in general (1=not satisfied, $10=$ very satisfied) 